\title{
Aktivitas Komunikasi Sanggar Seroja dalam Mengedukasi Transpuan di Jakarta
}

\author{
Frank Marco' ${ }^{1}$, Septia Winduwati ${ }^{2 *}$ \\ ${ }^{1}$ Fakultas Ilmu Komunikasi, Universitas Tarumanagara, Jakarta \\ Email: marcotakapente69@gmail.com \\ ${ }^{2}$ Fakultas Ilmu Komunikasi, Universitas Tarumanagara, Jakarta* \\ Email: septiaw@fikom.untar.ac.id
}

Masuk tanggal: 15-12-2021, revisi tanggal: 06-01-2022, diterima untuk diterbitkan tanggal: 16-01-2022

\begin{abstract}
Humans are social beings who need the help of other humans and every human being has the right to determine his own way of life. However, this is what thedoes not feel, lesbian gay bisexual transgender (LGBT) community especially the transwoman community, such as in the right to health, work and many more so that they have to live a different life because their choices are different from most people. Many of them drop out of school, do not work and fall into the world of crime, this can be an example of the lack of attention of the trans women community and is one of the main reasons for the establishment of Sanggar Seroja to educate and empower trans women in Jakarta. Sanggar Seroja tries to educate transgender women through art activities and activities of Micro, Small and Medium Enterprises (MSMEs). With the establishment of Sanggar Seroja, they hope that trans women will get the same attention and rights as other people, and they want to instill an attitude of independent trans women who are proud of themselves.
\end{abstract}

Keywords: education, group communication, transwomen

\begin{abstract}
Abstrak
Manusia adalah makluk sosial yang memerlukan bantuan manusia lain dan setiap manusia memiliki hak untuk menentukan jalan hidupnya sendiri. Namun inilah yang tidak dirasakan oleh komunitas lesbian gay bisexsual transgender (LGBT) terutama komunitas transpuan seperti dalam hak kesehatan, pekerjaan dan masih banyak lagi sehingga mereka harus menjalani hidup yang berbeda karena pilihannya yang berbeda dari kebanyakan orang. Banyak dari mereka yang putus sekolah, tidak bekerja dan terjerumus ke dalam dunia kriminalitas, hal ini dapat menjadi salah satu contoh kurangnya perhatian komunitas transpuan serta merupakan salah satu alasan utama didirikannya Sanggar Seroja untuk mengedukasi serta memberdayakan transpuan di Jakarta. Sanggar Seroja berusaha mengedukasi transpuan melalui kegiatan-kegiatan kesenian dan kegiatan Usaha Mikro Kecil Menengah (UMKM). Dengan didirikannya Sanggar Seroja, mereka berharap agar transpuan mendapatkan perhatian dan hak yang sama dengan orang lain, serta ingin menanamkan sikap transpuan yang independen dan bangga dengan dirinya sendiri. Pada penelitian ini, peneliti menggunakan metode penelitian kualitiatif deskriptif dengan menggunakan pendekatan studi kasus. Hasil pada penelitian ini adalah aktivitas komunikasi yang dibentuk oleh Sanggar Seroja komunikasi yang edukatif, saling terhubung dan juga Sanggar Seroja mengadakan kegiatan-kegiatan yang berguna untuk mengembangkan potensi dalam diri transpuan.
\end{abstract}

Kata Kunci: edukasi, komunikasi kelompok, transpuan 


\section{Pendahuluan}

Manusia merupakan makhluk sosial yang hidup berdampingan dan bergantung satu sama lain. Manusia hidup berkelompok dan menciptakan budaya yang diteruskan dari generasi ke generasi. Manusia yang hidup secara berkelompok pada suatu daerah dapat disebut juga sebagai masyarakat. Manusia dapat dikatakan masyarakat jika menjadi satu kesatuan golongan yang akan terus berhubungan dan berketergantungan (Nurmansyah, 2019).

Akan tetapi, meskipun masyarakat adalah sekelompok manusia yang saling bergantungan, masih ada sekelompok manusia yang tidak menjadi bagian dari kelompok masyarakat tersebut. Manusia yang tidak menjadi bagian dalam masyarakat akan terpinggirkan ataupun tersingkirkan, maka dapat dikatakan menjadi masyarakat marginal (pinggiran). Marginal sendiri berasal dari Bahasa Inggris yaitu marginal yang berarti pinggiran, kecil atau pun memiliki efek yang kecil.

Masyarakat marginal pun sering mengalami diskriminasi oleh masyarakat yang lebih besar atau mayoritas. Masyarakat yang masuk kedalam kategori marginal biasanya petani, pengemis, pemulung, anak jalanan dan masih banyak lagi. Konsep kaum marginal pun kini semakin luas cakupannya bukan hanya yang memiliki keterbatasan ekonomi serta pendidikan, keterbatasan ruang gerak di dalam lingkup sosial pun dapat dimasukan kedalam masyarakat marginal.

Komunitas LGBT juga sering mendapatkan diskriminasi sehingga memiliki keterbatasan ruang gerak di dalam masyarakat, kebanyakan dari mereka putus sekolah karena dirundung atau pun sudah merasa tidak nyaman dengan dirinya sendiri ada juga yang pergi dari keluarganya sehingga terputus dengan sumber biaya untuk melanjutkan pendidikan. Setelah mengalami diskirminasi di aspek pendidikan dan keluarga, komunitas LGBT juga tidak dapat bekerja karena mendapat diskriminasi di dunia profesional. Komunitas LGBT sering dihubungkan dengan penyakit HIV dan AIDS sehingga sering sulit mendapatkan pekerjaan yang memiliki kelas menengah ke atas seperti perusahaan.

Karena belum mendapatkan kesempatan yang sama, komunitas transpuan pun akhirnya bangkit untuk saling memberdayakan antara anggota komunitasnya. Terbentuk di tahun 2015, Sanggar Seroja ingin menyuarakan pendapat bahwa transpuan tidak perlu diolok-olok dan dikaitkan dengan dunia kriminal, Sanggar Seroja juga aktif di dalam kegiatan kesenian dan sering tampil di acara kebudayaan nasional. Di masa pandemi seperti ini Sanggar Seroja masih melakukan kampanye yang menumbuhkan keberanian kalangan transpuan yang lain untuk bersuara dan beropini melalui media sosial yang ada. Sanggar Seroja juga merangkul sesama komunitas LGBT terutama transpuan dan kalangan awam lewat seminar daring (webinar) mengenai kehidupan sebagai transpuan, tidak hanya seminar Sanggar Seroja juga melakukan kegiatan UMKM (usaha mikro kecil dan menengah) yaitu Dapur Madam Seroja dengan tujuan untuk memberikan kalangan transpuan kemampuan nonteknis (soft skill). Sanggar Seroja adalah grup transpuan yang aktif di dalam dunia kesenian seperti pementasan yang mengangkat kisah hasil elaborasi pengalaman pribadi setiap pemainnya.

Karena peneliti merasa isu ini menarik untuk diangkat maka dari itu peneliti tertarik untuk meneliti bagaimana proses komunikasi yang ada di dalam Sanggar Seroja dalam mengedukasi transpuan di Jakarta. Penelitian ini menggunakan teori komunikasi kelompok untuk mengetahui bentuk serta proses komunikasi yang ada 
Frank Marco, Septia Winduwati: Aktivitas Komunikasi Sanggar Seroja dalam Mengedukasi Transpuan di Jakarta

didalam kelompok ini. Untuk mengetahui komunikasi yang perlu dilakukan oleh Sanggar Seroja untuk mengedukasi kalangan transpuan di Jakarta.

\section{Metode Penelitian}

Dalam penelitian ini, peneliti memilih untuk menggunakan pendekatan deskriptif kualtiatif dengan metode etnografi karena dapat membantu peneliti memaknai proses interaksi di dalam suatu lingkungan serta peristiwa yang ada.

Creswell (Kusmarni, 2012) mengemukakan bahwa studi kasus sebuah proses penelusuran dari "suatu sistem yang terikat" atau "suatu kasus ataupun kasus yang beragam" yang seiring berjalannya waktu melalui pengumpulan data yang mendalam serta menggunakan berbagai sumber informasi yang "kaya" akan suatu hal/konteks. Penelitian kualtitatif menggunakan metode etnologi memungkinkan penulis untuk melakukan pengamatan secara lebih mendalam terhadap aktivitas komunikasi Sanggar Seroja dalam mengedukasi serta memberdayakan transpuan di Jakarta. Menurut (Moleong, 2012) penelitian kualitatif adalah penelitian yang bertujuan untuk memahami fakta tentang apa yang dialami oleh subjek/pelaku penelitian misalnya perilaku, persepsi, motivasi, tindakan, dll. Deskriptif adalah data berupa kata-kata, gambar, dan bukan angka-angka.

Subjek penelitian adalah tempat, barang atupun orang, tempat data untuk variabel penelitian menempel dan dipermasalahkan (Arikunto, 2016). Dalam penelitian ini subjek penelitian penulis adalah Sanggar Seroja. Objek adalah hal yang diselidiki selama kegiatan penelitian, objek juga bisa dikatakan hal yang menjadi titik perhatian sosial. (Sugiyono, 2018) menyebutkan ada tiga elemen yang dapat menjadi objek penelitian yaitu tempat, pelaku serta aktivitas. Objek pada penelitian ini adalah aktivitas komunikasi.

Teknik pengumpulan data yang digunakan dalam penelitian ini yaitu wawancara semi-terstruktur, dokumentasi dan studi kepustakaan. Wawancara adalah suatu proses interaksi antara pewawancara dengan informan atau orang yang diwawancarai melalui komunikasi secara langsung (Yusuf, 2015). (Sugiyono, 2018) menyebutkan dokumentasi adalah cara yang digunakan untuk memperoleh data serta informasi dalam bentuk dokumen, arsip, buku, angka serta gambar yang dapat menjadi laporan pendukung penelitian. Cara ini merupakan pelengkap dari penggunaan metode observasi ataupun wawancara agar menjadi lebih memiliki kredibilitas atau dapat dipercaya. Studi kepustakaan berhubungan dengan kajiankajian teoritis serta referensi lain yang berkaitan dengan, budaya, nilai dan juga norma yang tumbuh pada situasi sosial yang diteliti. Selain itu, studi kepustakaan sangat penting dalam melakukan penelitian, dikarenakan penelitian selalu berkaitan dengan kepustakaan ilmiah (Sugiyono, 2018). Miles dan Huberman (dalam Sugiyono, 2018) mengemukakan bahwa teknik pengolahan data kualitatif dapat dilakukan dengan melalui tiga tahap, yakni data reduction, data display, dan conclusion drawing/Verification.

Data yang didapatkan selama proses penelitian kualitatif tentu jumlahnya banyak. Oleh karena itu peneliti dapat melakukan reduksi data yang berarti merangkum, memilih hal utama serta lebih memfokuskan kepada hal-hal yang penting. Setelah direduksi, maka tahap selanjutnya adalah menyajikan data agar memiliki terlihat lebih jelas. Penyajian data yang dimaksud di sini dapat berbentuk tabel yang sederhana bisa berupa banyak hal contohnya grafik dan sejenisnya. Melalui penyajian data tersebut maka data lebih mudah untuk dilihat, tersusun, serta 
dipahami. Langkah ketiga dalam analisis data kualitatif menurut Miles dan Huberman adalah penarikan kesimpulan dan verifikasi.

\section{Hasil Temuan dan Diskusi}

\section{Komunikasi yang Dilakukan oleh Sanggar Seroja Untuk Mengedukasi Transpuan di Jakarta}

Komunikasi yang dilakukan oleh Sanggar Seroja adalah komunikasi kelompok yang saling terbuka, mendukung, saling mewadahi satu sama lain. Rikky mengatakan bahwa jika ada anggota yang tertarik untuk mendalami hal minat dan bakat, Sanggar Seroja akan membantu memfasilitasi hal tersebut. Mama Pandan menambahkan bahwa banyak komunitas atau yayasan lain menjadikan Sanggar Seroja sebagai acuan umum dalam menjadi komunitas yang baik. Sanggar Seroja pun tidak ada membedakan antara anggota senior dan anggota baru, mereka menganggap semua adalah sama dan semuanya patut untuk dihargai dan diperhatikan.

Menurut informan pertama, saat ini transpuan masih hanya menjadi bahan olok-olokan masyarakat, namun dengan adanya Sanggar Seroja komunitas transpuan mampu naik satu tingkat lebih baik daripada sebelumnya. Meskipun diolok atau dicibir komunitas transpuan masih bisa mengekspresikan diri lewat pementasanpementasan yang dihasilkan oleh Sanggar Seroja. Sanggar Seroja ingin mengajak komunitas transpuan untuk berani mengekspresikan diri, menceritakan kisah mereka lewat sudut pandang seni, menganalisa suatu naskah, melatih dalam dalam hal akting. Selain itu, Sanggar Seroja mengajak transpuan untuk berdiskusi, berkumpul agar setiap transpuan tidak merasa sendiri.

Sanggar Seroja juga mengadakan kampanye setiap tahunnya, pada bulan Juni 2021 lalu tema yang diusung oleh Sanggar Seroja adalah \#BanggaBegini untuk merayakan Pride Month. Dengan kampanye ini, Sanggar Seroja ingin mengajak komunitas LGBT terutama komunitas transpuan untuk bangga terhadap dirinya sendiri baik dari berbagai aspek seperti identitas dan juga kesenian. Banyak dari komunitas LGBT mengikuti kampanye tersebut untuk ikut berpartisipasi menyuarakan bahwa mereka bangga untuk menjadi dirinya sendiri. Selain kampanye, selama pandemi Sanggar Seroja juga aktif dalam mengadakan seminar daring dengan mengangkat topik-topik yang berhubungan dengan komunitas transpuan.

Dalam melakukan kegiatan, narasumber 2 menambahkan bahwa Sanggar Seroja tidak sendiri. Sanggar Seroja juga melakukan kolaborasi dengan instansi lain seperti Amnesty Indonesia, Auckland University dan masih banyak instansi lainnya, ia mengatakan bahwa Sanggar Seroja menjalin hubungan dengan pemangku kebijakan karena komunitas transpuan sering mendapatkan perlakuan yang diskriminatif, sehingga untuk mendapatkan akses fasilitas rumah sakit masih dipersulit dan juga dari segi fasilitas umum.

Upaya lain yang juga dilakukan oleh Sanggar Seroja adalah menjadi tempat bercerita bagi teman-teman anggota komunitas Sanggar Seroja, bagaimana menghadapi hal-hal yang tidak diinginkan seperti kekerasan, penghindaran diri dari konsumsi narkoba karena banyak dari teman-teman transpuan diluar sana yang masih mengkonsumsi obat-obatan terlarang sebelum bekerja dan juga lingkungan tempat tinggal yang lumayan rawan terhadap kriminalitas. 
Frank Marco, Septia Winduwati: Aktivitas Komunikasi Sanggar Seroja dalam Mengedukasi Transpuan di Jakarta

\section{Pembahasan}

Pada bagian ini peneliti akan membahas tentang kaitannya aktivitas komunikasi yang dilakukan oleh Sanggar Seroja dalam mengedukasi transpuan di Jakarta dengan teori serta konsep yang digunakan. Dalam penelitian ini penulis ingin mengetahui bagaimana proses komunikasi yang dilakukan Sanggar Seroja dalam mengedukasi transpuan. Karena, komunikasi adalah hal yang paling penting bagi individu atau lebih tanpa berkomunikasi, individu bahkan kelompok sekalipun tidak dapat memberikan suatu pesan untuk tercapainya tujuan mereka. Dari hasil temuan yang didapatkan peneliti, (Devito Joseph, 2011) berpendapat komunikasi mengacu kepada suatu tindakan yang dilakukan satu orang atau pun lebih, menyampaikan suatu pesan yang telah didistorsi, pesan yang dikirim dan diterima memiliki konteks atau makna serta tujuan dan tentunya memiliki pengaruh, proses ini juga memiliki umpan balik. Dapat disimpulkan bahwa Sanggar Seroja memiliki tujuan, yaitu untuk memberdayakan komunitas transpuan, komunikasi yang dijalin oleh Sanggar Seroja antar anggota komunitasnya adalah komunikasi yang baik, saling mendukung dan saling mengingatkan untuk terus berkembang untuk mengurangi stigma buruk yang ada di tengah masyarakat.

Dengan adanya komunikasi yang dijalin di dalam Sanggar Seroja, mereka mengajak anggotanya untuk berkembang melalui kegiatan-kegiatan yang diberikan. Komunitas transpuan mulai berusaha membuka lapangan pekerjaan baru seperti usaha kuliner berkat bantuan Sanggar Seroja sebagai wadah mereka berbisnis. Selain komunikasi yang dijalin antar anggota di dalam komunitas, Sanggar Seroja juga menjalin komunikasi keluar dengan instansi-instansi yang ada dengan tujuan untuk mempermudah atau membantu komunitas transpuan diterima oleh masyarakat dan mendapatkan hak yang sama tanpa ada diskriminasi. Sanggar Seroja menganggap bahwa komunikasi yang dijalin membantu komunitas transpuan dalam mengakses apa yang diperlukan seperti kesehatan, identitas, dan akses fasilitas umum. Edukasi yang diberikan oleh Sanggar Seroja sebenarnya cukup beragam dan bermanfaat bagi komunitas transpuan seperti kegiatan pementasan, seminar yang mengangkat topiktopik yang dirasakan serta mengajak transpuan untuk berkarya lewat kampanye yang diadakan setiap tahunnya.

Tentunya dalam penyampaian komunikasi pasti ada yang dinamakan noise atau gangguan dalam penyampaian komunikasi tersebut, bagi Sanggar Seroja noise yang ada adalah keterbelakangan edukasi yang didapat oleh komunitas transpuan karena kebayakan dari mereka tumbuh jauh dari masyarakat dan akses edukasi yang ada sehingga Sanggar Seroja terkadang merasa sulit dalam penyampaian pesan atau edukasi yang ada. Beberapa anggota komunitas masih sering memiliki prasangka yang kurang baik atau tidak tertarik dengan kegiatan edukasi yang diberikan. Meskipun begitu, masih ada anggota komunitas yang menghargai kegiatan yang diberikan dan tanggapan-tanggapan yang positif dari yayasan serta instansi yang telah menjalin kerjasama dan mendukung Sanggar Seroja.

Sanggar Seroja adalah sebuah kelompok atau yang di dalamnya terdapat anggota-anggota yang melakukan interaksi dan tentunya mengenal satu sama lain. Berdasarkan teori, kelompok adalah sekumpulan individu yang memiliki tujuan yang sama dan saling melakukan interaksi, saling berhubungan dan mengenal satu sama lain (Mulyana, 2014). Jika dikaitkan dengan pendapat (Hariadi, 2011) kelompok dapat dilihat dari segi persepsi, motivasi, tujuan, interdepedensi, serta segi interaksi. Yang berarti komunikasi kelompok akan menyamakan tujuan atau makna di dalam kelompok tersebut. Dengan berdirinya Sanggar Seroja, komunitas transpuan 
memiliki suatu motivasi karena Sanggar Seroja hadir untuk merangkul mereka sesama komunitas transpuan. Dari segi tujuan, Sanggar Seroja memiliki tujuan untuk mengedukasi komunitas transpuan agar bisa mengembangkan potensi mereka. Jika dilihat dari segi interdepedensi, Sesama anggota komunitas saling berketergantungan dan juga saling terhubung, dan terakhir komunitas transpuan dengan Sanggar Seroja memiliki hubungan yang saling mempengaruhi untuk terus belajar.

\section{Simpulan}

Penulis dapat menyimpulkan kesimpulan dari hasil penelitian yang dilakukan penulis adalah aktivitas komunikasi yang dilakukan Sanggar Seroja dalam mengedukasi transpuan di Jakarta yakni dengan cara kegiatan-kegiatan yang mampu menumbuhkan potensi dalam diri transpuan dalam berbagai bidang seperti bidang kesenian dan kuliner. Selain itu, Sanggar Seroja mengajak komunitas transpuan lewat kampanye yang ada untuk menumbuhkan rasa percaya diri komunitas transpuan. Sanggar Seroja juga menjalin komunikasi kelompok yang edukatif, saling terhubung, saling memotivasi, serta saling memberdayakan satu dengan yang lain sesama anggota komunitas. Dalam proses pengedukasian komunitas transpuan, Sanggar Seroja juga mengalami kendala seperti masih terdapat transpuan yang berprasangka buruk dan tidak peduli.

\section{Ucapan Terima Kasih}

Peneliti ingin mengucapkan terima kasih kepada Fakultas Ilmu Komunikasi Universitas Tarumanagara, narasumber, serta semua pihak yang turut membantu peneliti sehingga penelitian ini dapat diselesaikan.

\section{Daftar Pustaka}

Arikunto, S. (2016). Prosedur Penelitian: Suatu Pendekatan Praktik. Rineka Cipta. Moleong, L. J. (2012). Metodologi Penelitian Kualitatif. Rosdakarya.

Nurmansyah, G. (2019). Pengantar Antropologi: Sebuah Ikhtisar Mengenal Antropologi.

Sugiyono. (2018). Sugiyono Metode Penelitian Kuantitatif Kualitatif. Metode Penelitian Kuantitatif Kualitatif.

Yusuf, M. (2015). Metode Penelitian: Kuantitatif, Kualitatif, dan Penelitian Gabungan. Kencana Prenada Media Group. 